\title{
Development of SDS Modified Graphite Electrode for Effective Oxidation of Methanol and Ethanol
}

\section{Tajamal Hussain}

Institute of Chemistry, University of the Punjab, Lahore, Pakistan

Email:tjml786@yahoo.com

How to cite this paper: Hussain, T. (2016) Development of SDS Modified Graphite Electrode for Effective Oxidation of Methanol and Ethanol. Open Journal of Applied Sciences, 6, 853-859.

http://dx.doi.org/10.4236/ojapps.2016.613074

Received: October 7, 2016

Accepted: December 3, 2016

Published: December 6, 2016

Copyright $\odot 2016$ by author and Scientific Research Publishing Inc. This work is licensed under the Creative Commons Attribution International License (CC BY 4.0).

http://creativecommons.org/licenses/by/4.0/

\begin{abstract}
Methanol and ethanol fuel cells are getting important day by day because of energy crises. Main concern for fuel cell is the efficiency of the metal catalyst used for oxidation of methanol and ethanol. In this work, surfactant reformed electrodes by introducing sodium dodecyl sulphate (SDS), surfactant, at the surface of graphite electrodes along the metal nanoparticles were tried to develop. Idea behind it is to enhance the catalytic activity of metal nanoparticles through SDS. Modification of the graphite electrodes by SDS was characterized using Fourier transform infrared (FTIR) spectroscopy. Afterwards through electrochemical deposition, iron nanoparticles were got deposited on SDS modified and unmodified graphite electrodes which acted as catalyst. SDS modified iron deposited electrodes were utilized for the oxidation of methanol and ethanol in basic media. It was expected that SDS deposited at the surface of the electrodes would play an effective role in enhancing the rate of the oxidation reaction just by creating interaction between catalyst and reactant. Similar oxidation reaction was studied using unmodified iron deposited graphite electrode. Comparison of the results of oxidation reactions encourages the use of surfactant to speed up the oxidation reaction.
\end{abstract}

\section{Keywords}

Surfactant, Oxidation, Alcohol, SDS

\section{Introduction}

Nanomaterial is an interdisciplinary field of science which deals with the synthesis and characterization of nanoparticals of polymer or metals etc. Presence of nanomaterials in commercial products is increasing very rapidly [1] and a number of papers have been reported on their synthesis and properties [2] [3] [4]. In order to explore the potential 
applications of nanomaterials, inorganic nanoparticles like metals, their oxides and sulfides were introduced in the materials. Nanosized particles and their composites open a new class of materials with broad spectrum of applications. Various metal nanoparticles like silver, gold, copper nanopartiles are used in the production of novel devices [5]. Studies on zero, one, two, and three dimensional nanomaterials are still under progress [6] and it is reported that the dimensionality of the nanomaterials affects the catalytic behavior of the nanosheet composites [7]. Nanocomposites containing carbon are used as radar absorbing material (RAM) and microwave shielding systems [8]. Similarly electrospinning of nanomaterials is also getting attention of researchers because of its usage in electronic components and devices [9]. Researchers are trying to bring nanomaterials at low cost with environmentally friendly energy storage devices like supercapacitors. Different materials like inorganic nanoparticles (transition metal oxides), carbonaceous materials and conducting polymers have been used in supercapacitors [10]. Inorganic nanoparticles are getting attention of researchers remarkably because of their controlled way of preparation and different functionalities. These metal nanoparticles enhance the optical, magnetic, electrical and mechanical properties of the host materials significantly [11].

Metal nanoparticles play an important role in the field of catalysis as well. Most of the important chemicals production, involve catalysis like conversion of coal, crude oil and natural gas to fuels etc. Catalysts are proved to be environmentally friendly [12] as least amount of waste is generated as an end product. In the field of nanotechnology, size of the particles is decreasing smaller to the smallest and their properties are getting more and more attractive. Dimensions of the nanomaterial matter a lot especially when nanomaterial is employed as catalyst [13]. Many nano transition metals and metal complexes are used as catalysts [14] because of their $\mathrm{d}$ and $\mathrm{f}$ electron structures [15]. A number of publications related to applications of metal catalysts in fuel cell have been reported [16] [17] [18] and still research is under progress to increase the kinetics and efficiency with low cost. Keeping this in view, Basri et al. used the nanocatalyst for direct methanol-fuel cell (DMFC) [19]. In most of the papers, what main problem tried to address was enhancement in the catalytic ability of the metal catalyst used for the oxidation of methanol and ethanol in fuel cell. In continuation of solving this problem, we introduce SDS, surfactant, at the surface of electrode containing metal, catalyst in order to increase the interaction between catalyst and alcohol.

In present work, modification of the graphite electrodes accomplished through introducing SDS at the surface of electrode. SDS modification of the electrode was characterized by FTIR spectroscopy. Furthermore, iron nanoparticles got deposited at the surface of SDS modified electrodes electrochemically. Iron deposited SDS modified graphite electrodes were undergone for oxidation of methanol and ethanol. Idea behind introducing the SDS at the surface of the electrode is to increase the efficiency of catalytic iron nanoparticles deposited at electrode surface. Results of oxidations of methanol and ethanol for SDS modified and unmodified iron deposited graphite electrodes were compared. 


\section{Experimental}

\subsection{Chemicals and Instruments}

Sodiam dodecyl sulphate (Merck), iron (III) nitrate nona hydrate (Riedel-deHaen), methanol (sigma-aldrich) ethanol (sigma-aldrich) and sodium hydroxide (Merck) were used as received. FTIR spectrometer (Cary 630) of Agilent Technologies was used for characterization of the SDS adsorbed at the surface of the electrode.

\subsection{Surface Modification of Electrodes}

Surface modification of the electrode was done by introducing SDS at the surface of the electrode. For this purpose solution of the SDS was prepared and electrode was dipped more than two third in the solution of SDS. Electrode remained dip in the solution along magnetic stirring for $2 \mathrm{hrs}$. Afterwards, modified electrodes were washed with distilled water.

\subsection{FTIR Spectroscopic Study}

To study the adsorption of SDS at the surface of graphite electrode, FTIR spectroscopic analysis was done.

\subsection{Electrochemical Deposition of Iron}

For electrochemical deposition of iron at the surface of graphite electrode, solution of $0.4 \mathrm{M} \mathrm{Fe}\left(\mathrm{NO}_{3}\right)_{3} .9 \mathrm{H}_{2} \mathrm{O}$ was prepared in distilled water. To done electrochemical deposition of iron, two electrode cell was developed containing above mentioned solution as electrolytes i.e. $\mathrm{Fe}\left(\mathrm{NO}_{3}\right)_{3} .9 \mathrm{H}_{2} \mathrm{O}$. Deposition of iron was accomplished on SDS modified graphite electrode and unmodified graphite electrode.

\subsection{Oxidation Reaction of Methanol and Ethanol}

Electoroxidation of methanol and ethanol was carried out using $0.1 \mathrm{M}$ solution of methanol and ethanol, respectively, prepared in $0.1 \mathrm{M}$ solution of $\mathrm{NaOH}$. SDS modified iron deposited graphite electrode was taken as anode and simple graphite electrode was taken as cathode. Similar procedure was repeated by taking unmodified iron deposited graphite electrode as anode and simple graphite electrode as cathode.

\section{Result and Discussion}

\subsection{FTIR Spectroscopic Study}

FTIR spectrum of the layer removed from the SDS modified electrode is shown in Figure 1.

Two Important peaks in the region of $1100-1300 \mathrm{~cm}^{-1}$, corresponds to stretching vibration of $\mathrm{C}-\mathrm{O}$ bond and that of $-\mathrm{S}=\mathrm{O}$ of SDS. Another peak around $3000 \mathrm{~cm}^{-1}$ belongs to $-\mathrm{C}-\mathrm{H}$ bond [20].

\subsection{Oxidation of Methanol}

SDS modified iron deposited graphite electrode was used in two electrode cell for oxi- 
dation of methanol as anode while simple graphite electrode was taken as cathode. Electrolytic solution of $0.1 \mathrm{M}$ methanol was prepared in $0.1 \mathrm{M}$ aqueous $\mathrm{NaOH}$ solution. Values of the current were noted by varying the voltage applied. Similar procedure with identical setup was repeated with unmodified iron deposited graphite electrode. Comparative results for both types of iron deposited electrodes are as given in Figure 2. Very much obvious difference in current-voltage (I-V) curve is present for both electrodes. I-V curve for SDS modified iron deposited graphite electrode is sharper than that of unmodified iron deposited graphite electrode. This is because of the presence of SDS at the surface of electrode which played its role in creating interaction between catalyst and methanol.

\subsection{Oxidation of Ethanol}

As described above SDS modified iron deposited graphite electrode as anode was used for oxidation of ethanol in basic environment in two electrode cell. Simple graphite

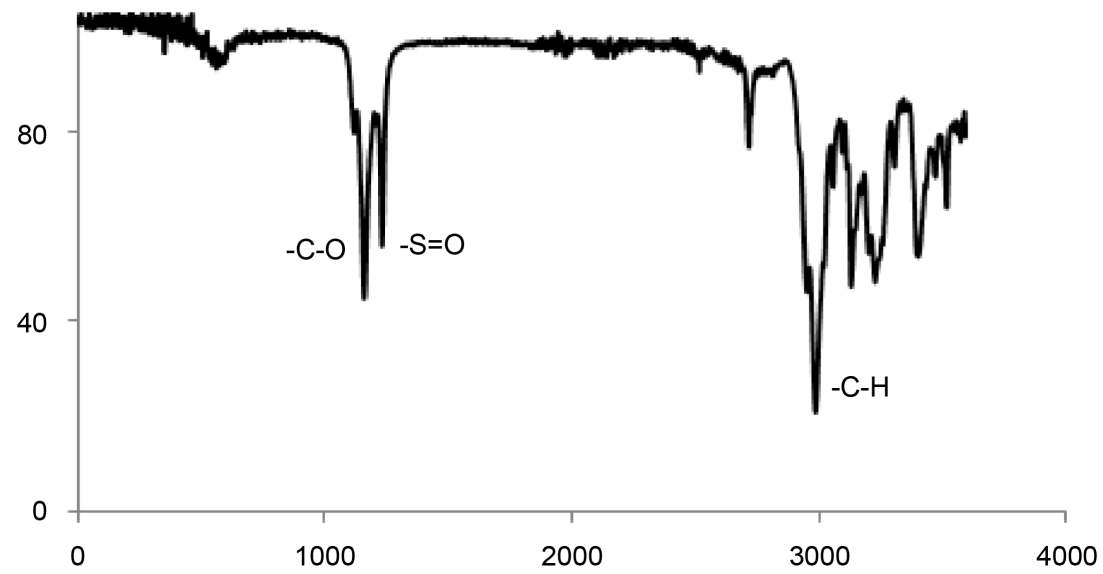

Figure 1. FTIR spectrum of layer removed from SDS modified graphite electrode.

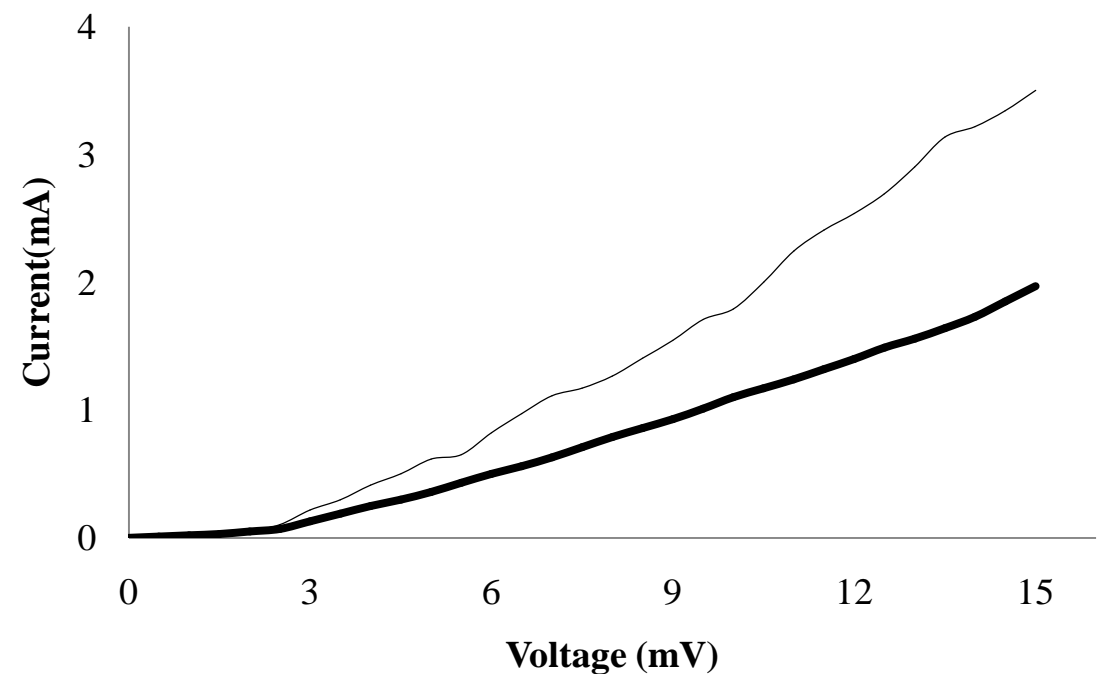

Figure 2. Plot of current vs. voltage for electroxidation of methanol for SDS modified (thin line) and SDS unmodified (thick line) iron deposited graphite electrode. 


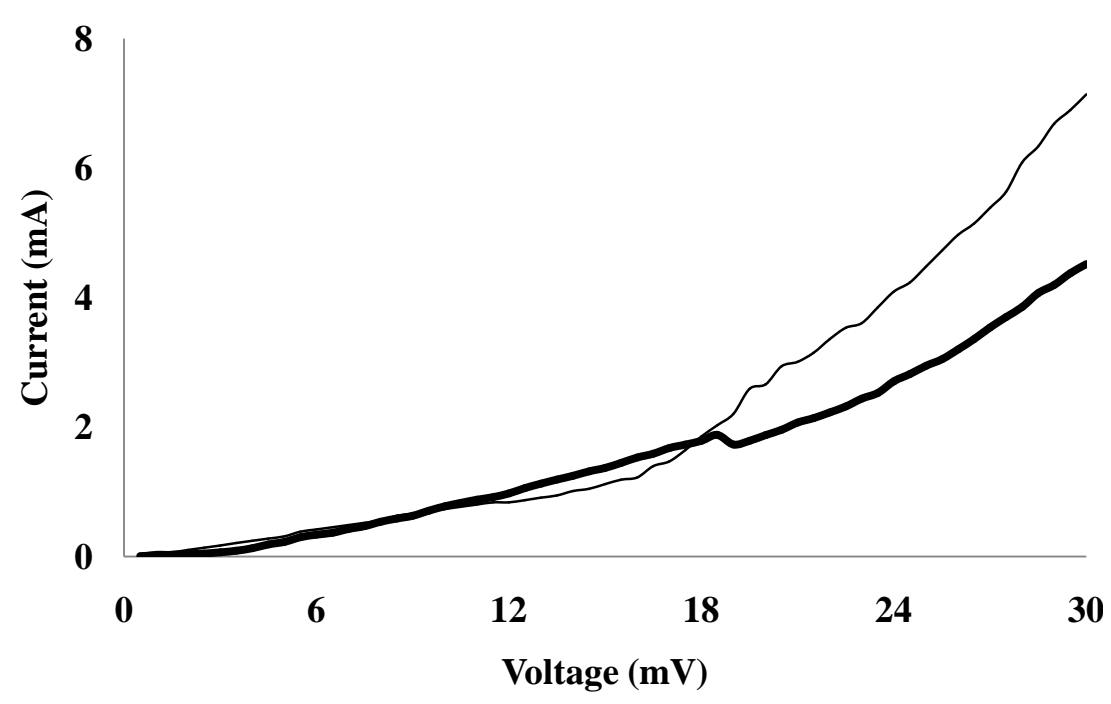

Figure 3. Plot of current vs. voltage for electroxidation of ethanol for SDS modified (thin line) and SDS unmodified (thick line) iron deposited graphite electrode.

electrode was taken as cathode. Electrolytic solution was comprised of $0.1 \mathrm{M}$ ethanol prepared in $0.1 \mathrm{M} \mathrm{NaOH}$ solution. Values of the current were measured as function of voltage applied. Whole procedure was repeated by having same experimental conditions and setup except unmodified iron deposited graphite electrode as anode. Results of these oxidations are shown in Figure 3. Like for oxidation of methanol, SDS modified iron deposited graphite electrode gives better results especially at higher potential. At lower potential region, rate of oxidation of ethanol is slow and same for both types of electrodes. This indicates that SDS played more effective role especially when required amount of activation energy is available.

\section{Conclusion}

SDS modified iron deposited and unmodified iron deposited graphite electrode has been developed. Modification of electrode has been done by simple adsorption of SDS at the surface of graphite electrode and confirmed by FTIR spectroscopy. SDS modified iron deposited graphite electrode was used for the oxidation of methanol and ethanol. Results of oxidation were compared with those of unmodified iron deposited graphite electrode. These comparative results indicate that overall performance of SDS modified graphite electrode for oxidation of both methanol and ethanol is far better as compared to unmodified iron deposited graphite electrodes. Efficiency of the SDS modified and unmodified electrodes is same at initial values of voltage. This is true for longer range of voltage for ethanol as compared to methanol. Use of other available surfactants is encouraged in place of SDS in future.

\section{Acknowledgements}

Author would like to thank University of the Punjab, Lahore for financial support to carry out present research work. 


\section{References}

[1] Colvin, V.L. (2003) The Potential Environmental Impact of Engineered Nanomaterials. Nature Biotechnology, 21, 1166-1170. https://doi.org/10.1038/nbt875

[2] Nozik, A. (2005) Exciton Multiplication and Relaxation Dynamics in Quantum Dots: Applications to Ultrahigh-Efficiency Solar Photon Conversion. Inorganic Chemistry, 44, 68936899. https://doi.org/10.1021/ic0508425

[3] Ouyang, M., Huang, J.-L. and Lieber, C.M. (2002) Fundamental Electronic Properties and Applications of Single-Walled Carbon Nanotubes. Accounts of Chemical Research, 35, 1018-1025. https://doi.org/10.1021/ar0101685

[4] Eustis, S. and El-Sayed, M.A. (2006) Why Gold Nanoparticles Are More Precious than Pretty Gold: Noble Metal Surface Plasmon Resonance and Its Enhancement of the Radiative and Nonradiative Properties of Nanocrystals of Different Shapes. Chemical Society Reviews, 35, 209-217. https://doi.org/10.1039/B514191E

[5] Sahu, D., Sarkar, N., Sahoo, G., Mohapatra, P. and Swain, S.K. (2015) Silver Imprinted Graphene Nanocomposites: Synthesisis and Morphological Study.

[6] Zhang, Q., Huang, J.Q., Qian, W.Z., Zhang, Y.Y. and Wei, F. (2013) The Road for Nanomaterials Industry: A Review of Carbon Nanotube Production, Post-Treatment, and Bulk Applications for Composites and Energy Storage. Small, 9, 1237-1265.

https://doi.org/10.1002/smll.201203252

[7] Liang, Y.T., Vijayan, B.K., Lyandres, O., Gray, K.A. and Hersam, M.C. (2012) Effect of Dimensionality on the Photocatalytic Behavior of Carbon-Titania Nanosheet Composites: Charge Transfer at Nanomaterial Interfaces. The Journal of Physical Chemistry Letters, 3, 1760-1765. https://doi.org/10.1021/jz300491s

[8] Micheli, D., Pastore, R., Apollo, C., Marchetti, M., Gradoni, G., Moglie, F. and Primiani, V.M. (2009) Carbon Based Nanomaterial Composites in RAM and Microwave Shielding Applications. IEEE 9 th IEEE Conference on Nanotechnology, 26-30 July 2009, Genoa, 226235.

[9] Miao, J., Miyauchi, M., Simmons, T.J., Dordick, J.S. and Linhardt, R.J. (2010) Electrospinning of Nanomaterials and Applications in Electronic Components and Devices. Journal of Nanoscience and Nanotechnology, 10, 5507-5519. https://doi.org/10.1166/jnn.2010.3073

[10] Jiang, H., Ma, J. and Li, C. (2012) Mesoporous Carbon Incorporated Metal Oxide Nanomaterials as Supercapacitor Electrodes. Advanced Materials, 24, 4197-4202. https://doi.org/10.1002/adma.201104942

[11] Hu, X. and Dong, S. (2008) Metal Nanomaterials and Carbon Nanotubes-Synthesis, Functionalization and Potential Applications towards Electrochemistry. Journal of Materials Chemistry, 18, 1279-1295. https://doi.org/10.1039/b713255g

[12] Murugadoss, A. and Chattopadhyay, A. (2007) A “Green” Chitosan-Silver Nanoparticle Composite as a Heterogeneous as Well as Micro-Heterogeneous Catalyst. Nanotechnology, 19, Article ID: 015603. https://doi.org/10.1088/0957-4484/19/01/015603

[13] Chaturvedi, S., Dave, P.N. and Shah, N.K. (2012) Applications of Nano-Catalyst in New Era. Journal of Saudi Chemical Society, 16, 307-325. https://doi.org/10.1016/j.jscs.2011.01.015

[14] Nacci, A., Cioffi, N., Gondela, E. and Walczak, K.Z. (2011) Special Issue: Nano-Catalysts and Nano-Technologies for Green Organic Synthesis. Molecules, 16, 1011-1916. https://doi.org/10.3390/molecules16021452

[15] Zhang, Z., Cui, Z., Chen, K.Z., Du, F.L. and Zhang, Z. (2000) Thin-Shell Structure of Na- 
nometal Particles. Materials Characterization, 44, 371-374.

https://doi.org/10.1016/S1044-5803(99)00074-1

[16] Chen, C., Yang, P., Lee, Y. and Lin, K. (2005) Fabrication of Electrocatalyst Layers for Direct Methanol Fuel Cells. Journal of Power Sources, 141, 24-29.

https://doi.org/10.1016/j.jpowsour.2004.09.011

[17] Chung, C.G., Kim, L., Sung, Y.W., Lee, J. and Chung, J.S. (2009) Degradation Mechanism of Electrocatalyst during Long-Term Operation of PEMFC. International Journal of $\mathrm{Hy}$ drogen Energy, 34, 8974-8981. https://doi.org/10.1016/j.ijhydene.2009.08.094

[18] Alcaide, F., Álvarez, G., Miguel, O., Lázaro, M.J., Moliner, R., López-Cudero, A., SollaGullón, J., Herrero, E. and Aldaz, A. (2009) Pt supported on Carbon Nanofibers as Electrocatalyst for Low Temperature Polymer Electrolyte Membrane Fuel Cells. Electrochemistry Communications, 11, 1081-1084. https://doi.org/10.1016/j.elecom.2009.03.023

[19] Basri, S., Kamarudin, S.K., Daud, W.R.W. and Yaakub, Z. (2010) Nanocatalyst for Direct Methanol Fuel Cell (DMFC). International Journal of Hydrogen Energy, 35, 7957-7970. https://doi.org/10.1016/j.ijhydene.2010.05.111

[20] Bharwaj, V., Chauhan, S. and Sharma, P. (2014) Probing Effect of Lipophilic Butylatedhydroxytoluene on Anionic Surfataant Proprties for Potential Food and Pharmaceutical Applications: Thermo-Acoustic and Spectroscopic Study. Fluid Phase Equilibria, 373, 63-71. https://doi.org/10.1016/j.fluid.2014.03.032

\section{Submit or recommend next manuscript to SCIRP and we will provide best service for you:}

Accepting pre-submission inquiries through Email, Facebook, LinkedIn, Twitter, etc. A wide selection of journals (inclusive of 9 subjects, more than 200 journals)

Providing 24-hour high-quality service

User-friendly online submission system

Fair and swift peer-review system

Efficient typesetting and proofreading procedure

Display of the result of downloads and visits, as well as the number of cited articles

Maximum dissemination of your research work

Submit your manuscript at: http://papersubmission.scirp.org/

Or contact ojapps@scirp.org 